University of Nebraska - Lincoln

DigitalCommons@University of Nebraska - Lincoln

Faculty Papers and Publications in Animal

Science

Animal Science Department

February 2002

\title{
Comparison of models for estimation of genetic parameters for mature weight of Hereford cattle
}

\author{
J. M. Rumph \\ University of Nebraska-Lincoln \\ R. M. Koch \\ University of Nebraska-Lincoln, rkoch1@unl.edu \\ K. E. Gregory \\ USDA, ARS, Roman L. Hruska U.S. Meat Animal Research Center \\ L. V. Cundiff \\ USDA, ARS, Roman L. Hruska U.S. Meat Animal Research Center \\ L. Dale Van Vleck \\ University of Nebraska-Lincoln, dvan-vleck1@unl.edu
}

Follow this and additional works at: https://digitalcommons.unl.edu/animalscifacpub

Part of the Animal Sciences Commons

Rumph, J. M.; Koch, R. M.; Gregory, K. E.; Cundiff, L. V.; and Van Vleck, L. Dale, "Comparison of models for estimation of genetic parameters for mature weight of Hereford cattle" (2002). Faculty Papers and Publications in Animal Science. 227.

https://digitalcommons.unl.edu/animalscifacpub/227

This Article is brought to you for free and open access by the Animal Science Department at DigitalCommons@University of Nebraska - Lincoln. It has been accepted for inclusion in Faculty Papers and Publications in Animal Science by an authorized administrator of DigitalCommons@University of Nebraska - Lincoln. 


\title{
Comparison of models for estimation of genetic parameters for mature weight of Hereford cattle ${ }^{1}$
}

\author{
J. M. Rumph*2, R. M. Koch*, K. E. Gregory $\dagger$, L. V. Cundiff $\dagger$, and L. D. Van Vleck $\dagger$ * \\ *Department of Animal Science, University of Nebraska, Lincoln 68583-0908 and USDA, ARS, \\ Roman L. Hruska U.S. Meat Animal Research Center, \\ $†$ Clay Center, NE 68933 and $\ddagger$ Lincoln, NE 68583-0908
}

\begin{abstract}
Genetic parameters of mature weight are needed for effective selection and genetic evaluation. Data for estimating these parameters were collected from 1963 to 1985 and consisted of 32,018 mature weight records of 4,175 Hereford cows that were in one control and three selection lines that had been selected for weaning weight, for yearling weight, or for an index combining yearling weight and muscle score for $22 \mathrm{yr}$. Several models and subsets of the data were considered. The mature weight records consisted of a maximum of three seasonal weights taken each year, at brand clipping (February and March), before breeding (May and June), and at palpation (August and September). Heritability estimates were high (0.49 to 0.86 ) for all models considered, which suggests that selection to change mature weight could be effective. The model that best fit the data included maternal genetic and maternal permanent environmental effects in addition to direct genetic and direct permanent environmental effects. Estimates of direct heritability with this model
\end{abstract}

ranged from 0.53 to 0.79 , estimates of maternal heritability ranged from 0.09 to 0.21 , and estimates of the genetic correlation between direct and maternal effects ranged from -0.16 to -0.67 for subsets of the data based on time of year that mature weight was measured. For the same subsets, estimates of the proportions of variance due to direct permanent environment and maternal permanent environment ranged from 0.00 to 0.09 and 0.00 to 0.06 , respectively. Using a similar model that combined all records and included an added fixed effect of season of measurement of mature weight, direct heritability, maternal heritability, genetic correlation between direct and maternal effects, proportion of variance due to direct permanent environmental effects, and proportion of variance due to maternal permanent environmental effects were estimated to be $0.69,0.13,-0.65,0.00$, and 0.04 , respectively. Mature weight is a highly heritable trait that could be included in selection programs and maternal effects should not be ignored when analyzing mature weight data.

Key Words: Beef Cattle, Growth, Heritability, Maternal Effects

(2002 American Society of Animal Science. All rights reserved.

J. Anim. Sci. 2002. 80:583-590

\section{Introduction}

Mature cow weight (MW) affects many aspects of production, including maintenance requirements (McMorris and Wilton, 1986; Montaño-Bermudez et al., 1990), reproduction (Buttram and Willham, 1989; Owens et al., 1993; Olson, 1994) and cull cow value, and therefore the profitability of the cow-calf operation. Because of impacts on many economic aspects of production, mature weight should be considered in selection programs. For selection to be effective, good estimates

\footnotetext{
${ }^{1}$ Published as paper no. 13275, Journal Ser., Nebraska Agric. Res. Div., Univ. of Nebraska, Lincoln 68583-0908.

${ }^{2}$ Correspondence: A218c Animal Science (phone: 402-472-6409; fax: 402-472-6362; E-mail: jrumph1@bigred.unl.edu).

Received February 20, 2001.

Accepted October 18, 2001.
}

of genetic parameters associated with mature weight must be available.

Previous estimates of direct heritability have been variable but generally have been moderate to high using various models (Johnson et al., 1990; Northcutt and Wilson, 1993; Kaps et al., 1999). Although several methods and models have been used to estimate components of variance for mature weight, maternal effects typically have not been included in models for mature weight (e.g., Johnson et al., 1990; Koots et al., 1994; Arango et al., 2000).

The objective of this study was to estimate components of variance for mature weight using models including maternal effects and weights taken at various times during the year.

\section{Materials and Methods}

Data were from one control and three selection lines of Hereford cattle developed at the Fort Robinson Beef 
Table 1. Number of observations for each line ${ }^{a}$ by year and weighing period ${ }^{b}$

\begin{tabular}{|c|c|c|c|c|c|c|c|c|c|c|c|c|}
\hline \multirow[b]{2}{*}{ Year } & \multicolumn{3}{|c|}{ WWL } & \multicolumn{3}{|c|}{ YWL } & \multicolumn{3}{|c|}{ IXL } & \multicolumn{3}{|c|}{ CTL } \\
\hline & $\mathrm{BC}$ & $\mathrm{BB}$ & $\mathrm{PA}^{\mathrm{c}}$ & $\mathrm{BC}$ & BB & $\mathrm{PA}^{\mathrm{c}}$ & $\mathrm{BC}$ & $\mathrm{BB}$ & $\mathrm{PA}^{\mathrm{c}}$ & $\mathrm{BC}$ & BB & $\mathrm{PA}^{\mathrm{c}}$ \\
\hline 1963 & - & 98 & 39 & - & 103 & 36 & - & 102 & 59 & - & - & - \\
\hline 1964 & 91 & 116 & 36 & 92 & 118 & 36 & 82 & 109 & 45 & - & - & - \\
\hline 1965 & 99 & 156 & 45 & 101 & 159 & 35 & 88 & 149 & 40 & - & - & - \\
\hline 1966 & 120 & 157 & 41 & 121 & 151 & 32 & 112 & 140 & 30 & - & - & - \\
\hline 1967 & 131 & 178 & 37 & 128 & 174 & 45 & 121 & 168 & 43 & - & - & - \\
\hline 1968 & 128 & 179 & 50 & 124 & 177 & 38 & 122 & 176 & 41 & - & - & - \\
\hline 1969 & 132 & 180 & 47 & 129 & 181 & 40 & 127 & 185 & 44 & - & - & - \\
\hline 1970 & 100 & 184 & - & 104 & 192 & 45 & 111 & 194 & 39 & - & - & - \\
\hline 1971 & 141 & 215 & 60 & 134 & 204 & 48 & 139 & 213 & 47 & - & - & - \\
\hline 1972 & 110 & 241 & 190 & 110 & 243 & 66 & 111 & 246 & 67 & - & 41 & 10 \\
\hline 1973 & 142 & 244 & 175 & 130 & 228 & - & 139 & 232 & - & 36 & 101 & - \\
\hline 1974 & 132 & 211 & 189 & 136 & 207 & 48 & 129 & 201 & 57 & 85 & 120 & 33 \\
\hline 1975 & - & 192 & 178 & - & 203 & 203 & - & 189 & 186 & - & 143 & 140 \\
\hline 1976 & 123 & 175 & 177 & 110 & 182 & 182 & 102 & 174 & 174 & 129 & 164 & 164 \\
\hline 1977 & 121 & 204 & 167 & 109 & 189 & 175 & 127 & 195 & 182 & 125 & 200 & 183 \\
\hline 1978 & 109 & 191 & 160 & 104 & 173 & 154 & 112 & 180 & 169 & 137 & 217 & 201 \\
\hline 1979 & 111 & 195 & 159 & 107 & 179 & 168 & 117 & 190 & 177 & 131 & 221 & 198 \\
\hline 1980 & 121 & 182 & 176 & 116 & 170 & 159 & 122 & 188 & 178 & 157 & 240 & 234 \\
\hline 1981 & 96 & 192 & 124 & 103 & 188 & 161 & 109 & 189 & 161 & 178 & 266 & 253 \\
\hline 1982 & 104 & 186 & - & 104 & 188 & 162 & 94 & 169 & 153 & 177 & 302 & 265 \\
\hline 1983 & 115 & 184 & - & 124 & 195 & 191 & 119 & 170 & 169 & 196 & 295 & 285 \\
\hline 1984 & 124 & 124 & - & 134 & 134 & 134 & 130 & 131 & 131 & 212 & 214 & 212 \\
\hline 1985 & - & 95 & - & - & 98 & - & - & 88 & - & - & 154 & - \\
\hline
\end{tabular}

${ }^{a}$ WWL, weaning weight selection line; YWL, yearling weight selection line; IXL, index selection line; and CTL, control line.

${ }^{\mathrm{b}} \mathrm{BC}$, brand clipping weight; $\mathrm{BB}$, before breeding weight; and PA, palpation weight.

${ }^{\mathrm{c}}$ Only yearling heifer weights were recorded at PA from 1963 to 1974; PA weights of all cows were recorded from 1975 to 1984.

Table 2. Mean weight $(\mathrm{kg})$ for each line ${ }^{\mathrm{a}}$ by year and weighing period ${ }^{\mathrm{b}}$

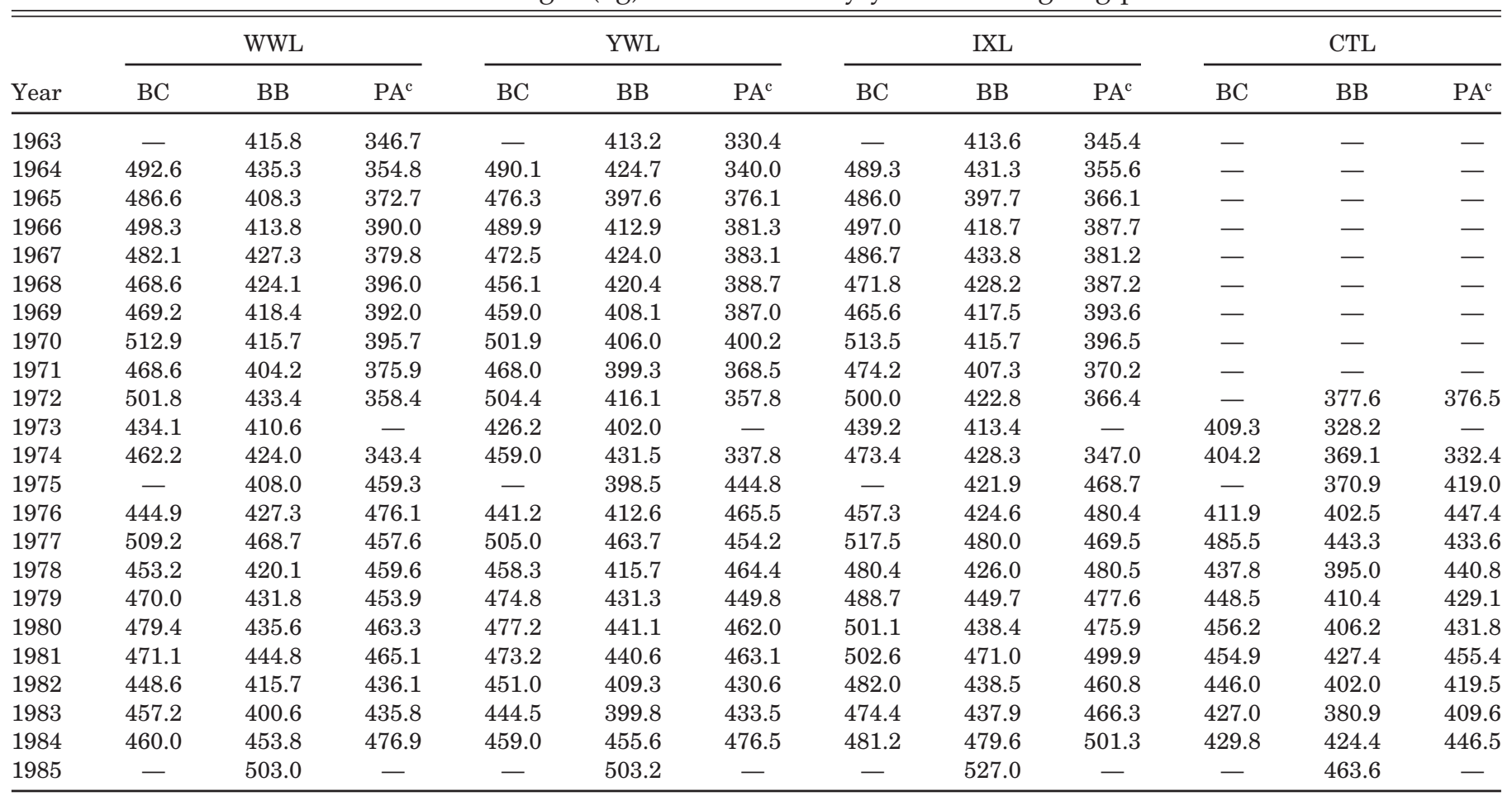

${ }^{a}$ WWL, weaning weight selection line; YWL, yearling weight selection line; IXL, index selection line; and CTL, control line.

${ }^{\mathrm{b}} \mathrm{BC}$, brand clipping weight; $\mathrm{BB}$, before breeding weight; and PA, palpation weight.

'Only yearling heifer weights were recorded at PA from 1963 to 1974; PA weights of all cows were recorded from 1975 to 1984. 
Cattle Research Station near Crawford, NE and later transferred to the U.S. Meat Animal Research Center (USMARC) in Clay Center, NE. Development and management of the lines has been described by Koch et al. (1974, 1994, 1995).

The selection lines were selected for 1) weaning weight (WWL), 2) yearling weight (YWL), or 3) an index (IXL) of yearling weight and muscle score from formation of the lines in 1960 from a single base population until 1982. More specifically, WWL cattle were selected on weight adjusted to $200 \mathrm{~d}$ and YWL cattle were selected on weight at $452 \mathrm{~d}$ (approximately $15 \mathrm{mo}$ ) of age for bulls and at $550 \mathrm{~d}$ (approximately $18 \mathrm{mo}$ ) of age for heifers. Originally, only bulls were evaluated for muscle score, but beginning in 1966 heifers were also evaluated and thus were selected for both muscle score and yearling weight in the IXL line from 1966 until the end of the experiment.

Cows were weighed a maximum of three times per year: at brand clipping (BC) in the late winter (February and March), which was also generally before calving, before being transferred to the breeding pasture (BB) in the late spring (May and June), and at palpation (PA) to determine pregnancy status shortly after calves were weaned in the late summer (August and September). The first possible weight recorded on yearling heifers was when they were transferred to breeding pastures, at approximately 15 mo of age. Only yearling heifers had weights recorded at palpation until 1974 . All females had weights recorded at palpation from 1975 until the end of the experiment. Management constraints at both locations dictated whether all weights were obtained each year. For each line, Tables 1 and 2 show the number of weights recorded and mean weights for each year and weighing period.

Selection ended with calves born in 1982, but data in this analysis included weights measured on cows through 1985. Weights were recorded on yearling through 13-yr-old females, but records were analyzed with weights divided into five groups based on age of cow: yearling, 2-yr-old, 3-yr-old, 4-yr-old, and mature cows (5 yr of age and older) as suggested by tests of least significant differences using GLM procedures of SAS (SAS Inst. Inc., Cary, NC), which showed no significant differences among ages of cows $5 \mathrm{yr}$ of age or older $(P<0.05)$. The number of cows with records and mean weights for each age and weighing period are shown in Tables 3 and 4.

Genetic parameters for mature weight were estimated using univariate and bivariate analyses for mixed models as described by Henderson (1984).

\section{Models}

Model 1. Model 1 was considered the full model and included direct and maternal genetic, direct permanent environmental, and maternal permanent environmental random effects. In matrix notation:

$$
\mathbf{y}=\mathbf{X} \boldsymbol{\beta}+\mathbf{Z}_{\mathrm{a}} \mathbf{a}+\mathbf{Z}_{\mathrm{m}} \mathbf{m}+\mathbf{Z}_{\mathrm{c}} \mathbf{c}+\mathbf{Z}_{\mathrm{d}} \mathbf{d}+\mathbf{e}
$$

where

$$
\begin{aligned}
& \mathbf{y} \text { is a vector of observations; } \\
& \boldsymbol{\beta} \text { is a vector of fixed effects; } \\
& \mathbf{a} \text { is a vector of direct genetic effects; } \\
& \mathbf{m} \text { is a vector of maternal genetic effects; } \\
& \mathbf{c} \text { is a vector of direct permanent environ- } \\
& \text { mental effects of the animal; } \\
& \mathbf{d} \text { is a vector of maternal permanent envi- } \\
& \text { ronmental effects of the dam; } \\
& \mathbf{e} \text { is a vector of random error effects; } \\
& \mathbf{X} \text { is a known incidence matrix associating } \\
& \text { fixed effects with records in } \mathbf{y} ; \text { and }
\end{aligned}
$$

$\mathbf{Z}_{\mathrm{a}}, \mathbf{Z}_{\mathrm{m}}, \mathbf{Z}_{\mathrm{c}}$, and $\mathbf{Z}_{\mathrm{d}}$ are known incidence matrices associating random effects with records in $\mathbf{y}$ with zero columns associated with animals in the pedigree that do not have records.

Furthermore,

$\mathrm{E}[\mathbf{y}]=\mathbf{X} \boldsymbol{\beta}$; and for the univariate (BC, $\mathrm{BB}$, or $\mathrm{PA})$ version of Model 1:

$$
\operatorname{Var}\left[\begin{array}{c}
\mathbf{a} \\
\mathbf{m} \\
\mathbf{c} \\
\mathbf{d} \\
\mathbf{e}
\end{array}\right]=\left[\begin{array}{ccccc}
\mathbf{A} \sigma_{a}^{2} & \mathbf{A} \sigma_{a m} & 0 & 0 & 0 \\
\mathbf{A} \sigma_{a m} & \mathbf{A} \sigma_{m}^{2} & 0 & 0 & 0 \\
0 & 0 & \mathbf{I} \sigma_{c}^{2} & 0 & 0 \\
0 & 0 & 0 & \mathbf{I} \sigma_{d}^{2} & 0 \\
0 & 0 & 0 & 0 & \mathbf{I} \sigma_{e}^{2}
\end{array}\right]
$$

where matrix $\mathbf{A}$ is the numerator relationship matrix of all 14,468 animals in the pedigree, including those without records, and the $\mathbf{I}$ are identity matrices of appropriate order; $\sigma_{\mathrm{a}}^{2}$ is variance due to additive genetic effects of the cow; $\sigma_{\mathrm{m}}^{2}$ is variance due to maternal genetic effects; $\sigma_{c}^{2}$ is variance due to permanent environmental effects of the cow; $\sigma_{\mathrm{d}}^{2}$ is variance due to maternal permanent environmental effects of her dam; and $\sigma_{\mathrm{e}}^{2}$ is variance due to random error.

The (co)variance structure for bivariate analyses for weights $i$ and $j$ using Model $1(i / j=\mathrm{BC} / \mathrm{BB}, \mathrm{BC} / \mathrm{PA}$, or $\mathrm{BB} / \mathrm{PA})$ is:

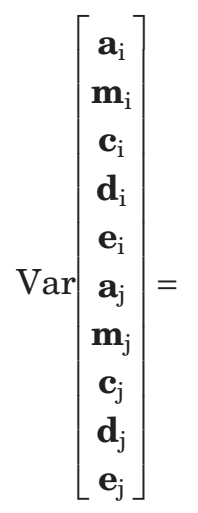


Table 3. Number of weight records for each line ${ }^{a}$ by age at weighing and weighing period $^{b}$

\begin{tabular}{|c|c|c|c|c|c|c|c|c|c|c|c|c|}
\hline \multirow[b]{2}{*}{ Age, yr } & \multicolumn{3}{|c|}{ WWL } & \multicolumn{3}{|c|}{ YWL } & \multicolumn{3}{|c|}{ IXL } & \multicolumn{3}{|c|}{ CTL } \\
\hline & $\mathrm{BC}$ & $\mathrm{BB}$ & $\mathrm{PA}$ & $\mathrm{BC}$ & $\mathrm{BB}$ & PA & $\mathrm{BC}$ & $\mathrm{BB}$ & PA & $\mathrm{BC}$ & $\mathrm{BB}$ & PA \\
\hline 1 & - & 964 & 969 & - & 971 & 971 & - & 943 & 967 & - & 686 & 602 \\
\hline 2 & 506 & 714 & 352 & 501 & 703 & 348 & 490 & 676 & 340 & 450 & 520 & 407 \\
\hline 3 & 475 & 553 & 247 & 468 & 535 & 255 & 478 & 558 & 265 & 330 & 426 & 355 \\
\hline 4 & 412 & 483 & 203 & 396 & 471 & 205 & 393 & 471 & 207 & 282 & 350 & 270 \\
\hline 5 & 318 & 401 & 139 & 327 & 415 & 137 & 331 & 404 & 155 & 213 & 270 & 220 \\
\hline 6 & 264 & 316 & 91 & 276 & 318 & 103 & 269 & 317 & 109 & 153 & 205 & 164 \\
\hline 7 & 211 & 248 & 73 & 201 & 238 & 55 & 207 & 242 & 59 & 93 & 127 & 93 \\
\hline 8 & 164 & 190 & 49 & 151 & 172 & 37 & 145 & 178 & 48 & 42 & 57 & 42 \\
\hline 9 & - & 115 & 32 & - & 112 & 31 & - & 113 & 28 & - & 31 & 22 \\
\hline 10 & - & 51 & 13 & - & 57 & 13 & - & 53 & 14 & - & 5 & 3 \\
\hline 11 & - & 28 & 2 & - & 27 & 2 & - & 21 & - & - & 1 & - \\
\hline 12 & - & 10 & 3 & - & 12 & 1 & - & 2 & - & - & - & - \\
\hline 13 & - & 6 & - & - & 5 & - & - & - & - & - & - & - \\
\hline $5-13^{\mathrm{c}}$ & 957 & 1,365 & 402 & 955 & 1,356 & 379 & 952 & 1,330 & 413 & 501 & 696 & 544 \\
\hline
\end{tabular}

${ }^{a}$ WWL, weaning weight selection line; YWL, yearling weight selection line; IXL, index selection line; and CTL, control line.

${ }^{\mathrm{b}} \mathrm{BC}$, brand clipping weight; $\mathrm{BB}$, before breeding weight; and $\mathrm{PA}$, palpation weight.

${ }^{\mathrm{c}} \mathrm{For}$ all analyses, ages $5 \mathrm{yr}$ and older were considered mature cows.

$$
\left[\begin{array}{cccccccccc}
\mathbf{A} \sigma_{a i}^{2} & \mathbf{A} \sigma_{\text {aimi }} & 0 & 0 & 0 & \mathbf{A} \sigma_{\text {aiaj }} & \mathbf{A} \sigma_{\text {aimj }} & 0 & 0 & 0 \\
\mathbf{A} \sigma_{\text {aimi }} & \mathbf{A} \sigma_{m i}^{2} & 0 & 0 & 0 & \mathbf{A} \sigma_{a j m i} \mathbf{A} \sigma_{m i m j} & 0 & 0 & 0 \\
0 & 0 & \mathbf{I} \sigma_{c i}^{2} & 0 & 0 & 0 & 0 & \mathbf{I} \sigma_{c i c j} & 0 & 0 \\
0 & 0 & 0 & \mathbf{I} \sigma_{d i}^{2} & 0 & 0 & 0 & 0 & \mathbf{I} \sigma_{d i d j} & 0 \\
0 & 0 & 0 & 0 & \mathbf{I} \sigma_{e i}^{2} & 0 & 0 & 0 & 0 & \mathbf{I} \sigma_{\text {eiej }} \\
\mathbf{A} \sigma_{\text {aiaj }} & \mathbf{A} \sigma_{\text {ajmi }} & 0 & 0 & 0 & \mathbf{A} \sigma_{a j}^{2} & \mathbf{A} \sigma_{a j m j} & 0 & 0 & 0 \\
\mathbf{A} \sigma_{a i m j} \mathbf{A} \sigma_{m i m j} & 0 & 0 & 0 & \mathbf{A} \sigma_{a j m j} & \mathbf{A} \sigma_{m j}^{2} & 0 & 0 & 0 \\
0 & 0 & \mathbf{I} \sigma_{c i c j} & 0 & 0 & 0 & 0 & \mathbf{I} \sigma_{c j}^{2} & 0 & 0 \\
0 & 0 & 0 & \mathbf{I} \sigma_{d i d j} & 0 & 0 & 0 & 0 & \mathbf{I} \sigma_{d j}^{2} & 0 \\
0 & 0 & 0 & 0 & \mathbf{I} \sigma_{e i e j} & 0 & 0 & 0 & 0 & \mathbf{I} \sigma_{e j}^{2}
\end{array}\right]
$$

Model 2. Model 2 is identical to the full model except that maternal genetic effects were not included sepa- rately in the model so that neither the maternal genetic variance nor the covariance involving maternal genetic effects could be estimated. With Model 2, the vector of maternal effects, $\mathbf{d}$, included the sum of maternal genetic and permanent environmental effects of the dam.

Model 3. Model 3 is a reduced version of both Models 1 and 2 with vectors for both maternal genetic effects and maternal permanent environmental effects excluded with the only random factors being direct genetic and permanent environmental effects.

Based on significant effects found using the GLM procedure in SAS (SAS Inst. Inc.), four fixed factors were included in Models 1 through 3. The first three factors were two-way subclass effects for line with birth and method of rearing for the calf born that year

Table 4. Mean weight $(\mathrm{kg})$ for each line $\mathrm{a}^{\mathrm{a}}$ by age and weighing period

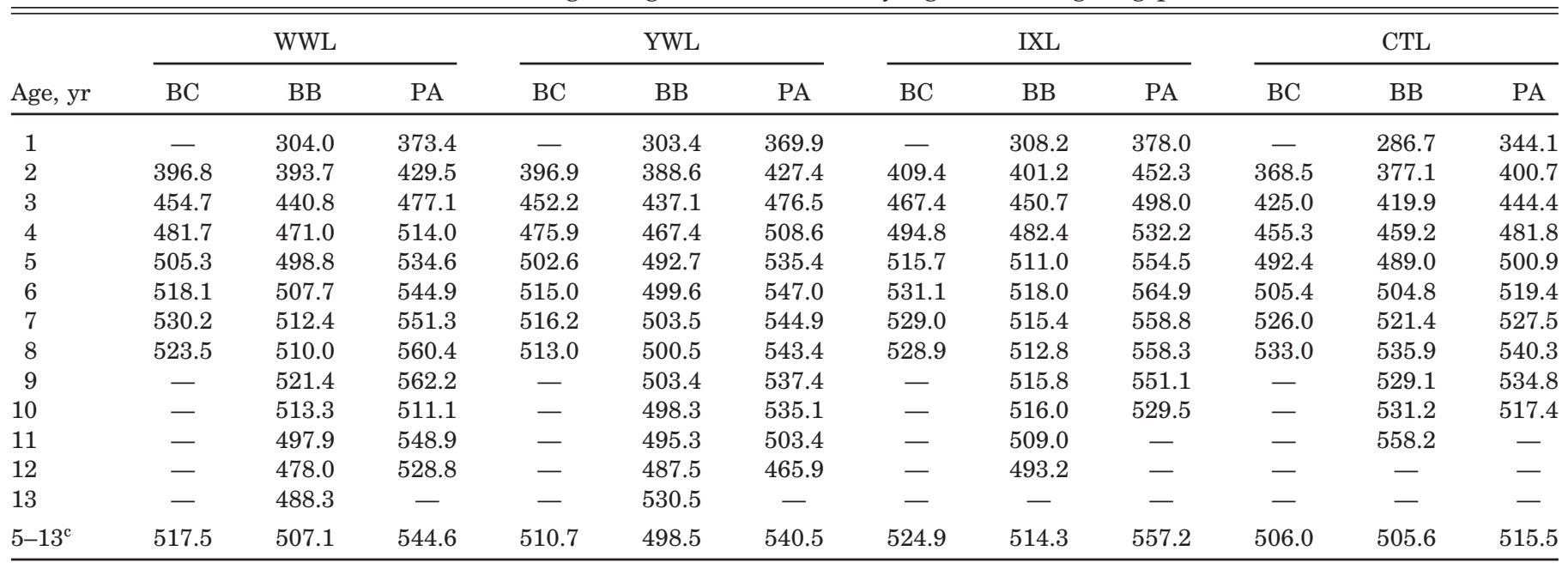

${ }^{a}$ WWL, weaning weight selection line, YWL, yearling weight selection line; IXL, index selection line; and CTL, control line.

${ }^{\mathrm{b}} \mathrm{BC}$, brand clipping weight; $\mathrm{BB}$, before breeding weight; and PA, palpation weight.

${ }^{\mathrm{c}} \mathrm{For}$ all analyses, ages five and older were considered mature cows. 
Table 5. Likelihood values (-2logL) for models from univariate and bivariate analyses of mature weight measured at different times of the year

\begin{tabular}{|c|c|c|c|}
\hline \multirow[b]{2}{*}{ Season(s) } & \multicolumn{3}{|c|}{ Univariate analyses } \\
\hline & Model $1^{\mathrm{a}}$ & Model $2^{\mathrm{b}}$ & Model $3^{\mathrm{c}}$ \\
\hline \multirow{4}{*}{$\begin{array}{l}\mathrm{BC}^{\mathrm{d}} \\
\mathrm{BB}^{\mathrm{d}} \\
\mathrm{PA}^{\mathrm{d}}\end{array}$} & $76,569.17^{\mathrm{e}}$ & $76,628.01^{\mathrm{f}}$ & $76,669.31^{\mathrm{g}}$ \\
\hline & $132,772.15^{\mathrm{e}}$ & $132,921.33^{\mathrm{f}}$ & $133,103.28^{\mathrm{g}}$ \\
\hline & $79,108.48^{\mathrm{e}}$ & $79,183.48^{f}$ & $79,314.84^{\mathrm{g}}$ \\
\hline & Model $4^{\mathrm{a}}$ & Model $5^{\mathrm{b}}$ & Model $6^{\mathrm{c}}$ \\
\hline \multirow[t]{2}{*}{ All } & $293,055.23^{\mathrm{e}}$ & $293,211.76^{\mathrm{f}}$ & $293,410.57^{\mathrm{g}}$ \\
\hline & \multicolumn{3}{|c|}{ Bivariate analyses } \\
\hline Seasons & Model $1^{\mathrm{a}}$ & Model $2^{\mathrm{b}}$ & Model $3^{\mathrm{c}}$ \\
\hline $\mathrm{BC}, \mathrm{BB}$ & $203,231.78^{\mathrm{e}}$ & $203,283.44^{\mathrm{f}}$ & $203,449.29^{\mathrm{g}}$ \\
\hline $\mathrm{BC}, \mathrm{PA}$ & $152,970.58^{\mathrm{e}}$ & $152,999.82^{\mathrm{f}}$ & $153,136.69^{g}$ \\
\hline $\mathrm{BB}, \mathrm{PA}$ & $204,775.27^{\mathrm{e}}$ & $204,832.78^{\mathrm{f}}$ & $204,914.67^{\mathrm{g}}$ \\
\hline \multicolumn{4}{|c|}{$\begin{array}{l}\text { anandom effects included in Models } 1 \text { and } 4 \text { are direct genetic of the animal, maternal genetic of the dam, } \\
\text { direct permanent environment of the animal, and maternal permanent environment of the dam. } \\
\text { b Random effects included in Models } 2 \text { and } 5 \text { are direct genetic of the animal, direct permanent environment } \\
\text { of the animal, and combined maternal of the dam. } \\
\text { cRandom effects included in Models } 3 \text { and } 6 \text { are direct genetic of the animal and direct permanent } \\
\text { environment of the animal. } \\
{ }^{d} \text { BC, brand clipping weight; BB, before breeding weight; and PA, palpation weight. } \\
\text { e,f,g Values in the same row with different superscripts are significantly different }(P<0.05) \text {. }\end{array}$} \\
\hline
\end{tabular}

$(\mathbf{B M R} \times \mathbf{L})$, with age of cow's dam $(\mathbf{D A} \times \mathbf{L})$, and with pregnancy status prior to $\mathrm{BC}(\mathbf{P} \times \mathbf{L})$. The fourth fixed factor was a three-way subclass effect of year by age of cow by line $(\mathbf{Y} \times \mathbf{A} \times \mathbf{L})$.

The age of dam used for $\mathrm{DA} \times \mathrm{L}$ was the age of the dam in years when the cow with mature weight measurements was born. On the other hand, the age of the cow used for the $\mathrm{Y} \times \mathrm{A} \times \mathrm{L}$ subclass was edited to create five age groups, as described previously. A linear and quadratic covariate for the number of days between when the weight was taken and when the cow calved was also included in the model. If a female did not calve that particular year or was a heifer, this covariate was zero.

Models 4 to 6. The first three models were used with both univariate and bivariate analyses for weights taken at the three times of the year as separate traits. Because, as expected, there were high correlations between weights taken in the same year on the same cow, another set of univariate models was also used for combined analyses of weights from all three periods. These models included a fixed factor of season by line $(\mathbf{S} \times \mathbf{L})$, as shown in Tables 5 and 6 , where season was defined as the period when the weight was taken: $\mathrm{BC}, \mathrm{BB}$, or PA. These models are classified as Models 4 to 6 . Model 4 is the full model and is identical to Model 1, except for the added fixed factor. Similarly, Model 5 is identical to Model 2 and Model 6 is identical to Model 3, but with the $\mathrm{S} \times \mathrm{L}$ factor included in Models 5 and 6 . The expectations and (co)variance structures for these models are the same as for the univariate analyses for Models 1 to 3 , with the exception that the $\beta$ vector contains the additional fixed factor of $\mathrm{S} \times \mathrm{L}$.

\section{Estimation of Variance Components}

(Co)variance components were estimated using Models 1 to 6 with the multiple-trait derivative-free REML program (MTDFREML) of Boldman et al. (1993) modified by Dodenhoff et al. (1998) for calculation of standard errors of estimates of genetic parameters for certain models. For the first start, the convergence criterion (variance of the simplex) was set at $1 \times 10^{-6}$. Once the interim convergence criterion was reached, cold restarts were continued until minus twice the logarithm of the likelihood (-2logL) differed by less than $1 \times$ $10^{-2}$ between successive restarts.

\section{Estimation of Standard Errors}

Standard errors for the estimates of parameters for multiple-trait analyses could be computed only when there were no missing observations, so that standard errors could not be obtained from the bivariate analyses of data for Models 1 to 3. To obtain estimates of the standard errors for the bivariate analyses, the data were edited to include only cows that had observations for both weights used in an analysis. The MTDFREML program was then run using the final results from the full analysis as starting values. These approximations for the standard error estimates should be conservative estimates because less information was used to obtain the standard errors than to obtain the estimates of genetic parameters. 
Table 6. Estimates of parameters ${ }^{\mathrm{a}}$ (and standard errors) from univariate and bivariate analyses using Models 1 and 4

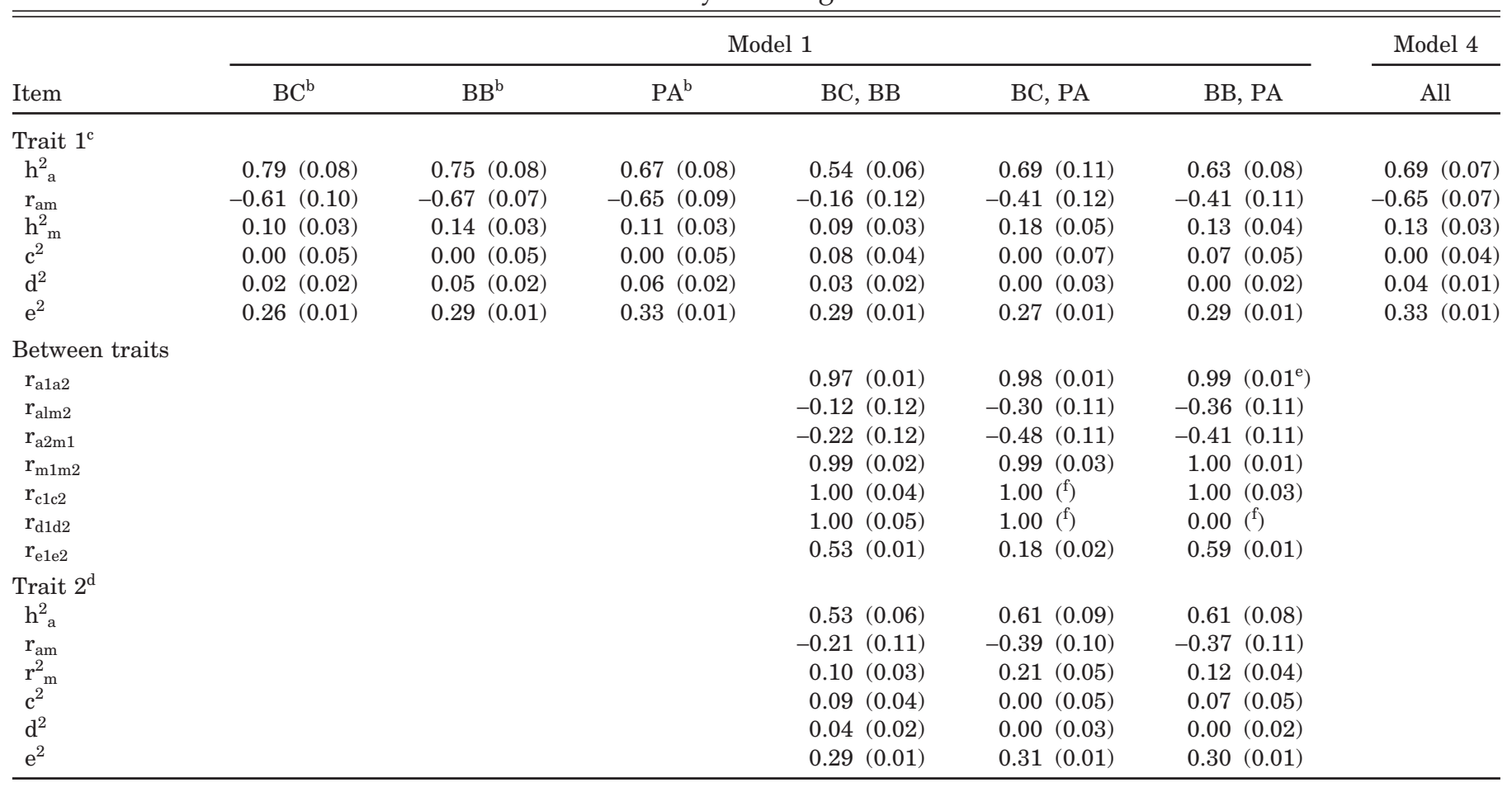

${ }^{\mathrm{a}}$ Genetic parameters: $\mathrm{h}_{\mathrm{a}}^{2}$, direct heritability; $\mathrm{r}_{\mathrm{am}}$, correlation between direct genetic and maternal genetic effects; $\mathrm{h}_{\mathrm{m}}^{2}$, maternal heritability; $c^{2}$, proportion of variance due to direct permanent environmental effects; $\mathrm{d}^{2}$, proportion of variance due to maternal permanent environmental effects; $\mathrm{e}^{2}$, proportion of variation due to temporary environmental effects; $\mathrm{r}_{\mathrm{a} 1 \mathrm{a} 2}$, correlation between direct genetic effects for traits 1 and 2 ; $\mathrm{r}_{\mathrm{a} 1 \mathrm{~m} 2}$, correlation between direct genetic effects of trait 1 and maternal genetic effects of trait $2 ; \mathrm{r}_{\mathrm{a} 2 \mathrm{~m} 1}$, correlation between direct genetic effects of trait 2 and maternal genetic effects of trait $1 ; r_{\mathrm{m} 1 \mathrm{~m} 2}$, correlation between maternal genetic effects of traits 1 and $2 ; \mathrm{r}_{\mathrm{c} 1 \mathrm{c} 2}$, correlation between direct permanent environmental effects of traits 1 and $2 ; \mathrm{r}_{\mathrm{d} 1 \mathrm{~d} 2}$, correlation between maternal permanent environmental effects of traits 1 and 2 ; and $\mathrm{r}_{\mathrm{e} 1 \mathrm{e} 2}$, correlation between temporary environmental effects of traits 1 and 2 .

${ }^{\mathrm{b}} \mathrm{BC}$ : brand clipping weight; BB: before breeding weight; and PA: palpation weight.

'Trait 1 in a bivariate analysis is defined as the first trait listed in the column header.

${ }^{\mathrm{d}}$ Trait 2 in a bivariate analysis is defined as the second trait listed in the column header.

eApproximate standard error for this estimate was less than 0.005 but was rounded up to 0.01 .

${ }_{\mathrm{f}}^{\mathrm{f}}$ Approximate standard error for this estimate was outside the theoretical bounds $(>1.00)$.

\section{Results and Discussion}

\section{Comparison of Models}

Table 5 shows the $-2 \log L$ values for the final run for each analysis. For the univariate analyses, Models 1 and 2 are significantly different $(P<0.05)$ if the difference in $-2 \log \mathrm{L}$ between the two models is greater than 5.99 based on a $\chi^{2}$ test with two degrees of freedom (Ramsey and Schafer, 1997). For all three analyses using these models, Model 1 was significantly better, given the data, than Model 2. The difference in -2logL between Models 2 and 3 must be greater than 3.84 to be significant when using a $\chi^{2}$ test with one degree of freedom $(P<0.05)$. For all three analyses Model 2 was significantly better, given the data, than Model 3.

For bivariate analyses, the difference between $-2 \log \mathrm{L}$ for Models 1 and 2 must be greater than 14.07 to be significant for a $\chi^{2}$ test with seven degrees of freedom and the difference between Models 2 and 3 must be greater than 7.81 to be significant for a $\chi^{2}$ test with three degrees of freedom $(P<0.05)$. For all analyses using these models, Model 1 was significantly better, given the data, than Model 2, and Model 2 was significantly better than Model 3.

For comparison of Models 4, 5, and 6, the critical values for the $\chi^{2}$ test are the same as for the univariate analyses with Models 1, 2, and 3, respectively, because the number of variance components are the same as for Models 1, 2, and 3. Table 5 also shows that, as with the models without the $\mathrm{S} \times \mathrm{L}$ factor, Model 4 best fit the data, followed by Model 5, and then by Model 6; the differences in $-2 \operatorname{logL}$ between models was statistically significant $(P<0.05)$.

Due to the significance of Model 1 compared with Models 2 and 3 and Model 4 compared with Models 5 and 6 , only results from Models 1 and 4 will be discussed in depth. In general, estimates of direct heritability were inflated with Model 2 compared with Model 1 and with Model 5 compared with Model 4. Additionally, because maternal genetic effects were not included in Models 2 and 5, the portion of variance due to dam (sum of maternal genetic and maternal permanent environmental) effects in these models increased to accommodate the maternal genetic component. With Models 3 and 6, the models that excluded all maternal effects, the direct heri- 
tability estimates were also inflated relative to Models 1 and 4 . This increase is most likely due to maternal effects inflating the estimate of direct heritability.

\section{Genetic Parameters}

Model 1. The estimates with the full model for each of the three weighing periods analyzed separately and for bivariate analyses for weights taken in a pair of seasonal weighing periods are shown in Table 6 . The estimates from all six of these analyses are generally similar. Direct heritability estimates (and standard errors) for the univariate analyses were $0.79(0.08), 0.75$ (0.08), and $0.67(0.08)$ for $\mathrm{BC}, \mathrm{BB}$, and PA weights, respectively. With the bivariate analyses, direct heritability estimates were somewhat smaller and ranged from $0.53(0.06)$ to $0.69(0.11)$. These estimates are in agreement with those reported by various authors, including Brinks et al. (1962), Bullock et al. (1993), and Kaps et al. (1999), and are larger than the current estimate of 0.49 that is used by the American Angus Association for their genetic evaluations (AAA, 2000), the only breed association known to be reporting expected progeny differences (EPD) for mature weight.

Estimates of maternal heritability were larger than expected. With the univariate analyses, estimates were 0.10 (0.03), 0.14 (0.03), and 0.11 (0.03) for BC, BB, and PA weights, respectively. With the bivariate analyses, estimates of maternal heritability ranged from 0.09 $(0.03)$ to $0.21(0.05)$. The relatively high estimates for the maternal genetic component, in addition to the likelihood values in Table 5, which show Model 1 to be significantly better than models without a maternal genetic effect, suggest that maternal effects should be considered when doing genetic evaluations of beef cattle for mature weight. In contrast, Arango et al. (2000) found that maternal genetic effects were negligible for mature weight of crossbred cows. In other previous studies, maternal effects for mature weight were not included in the model (e.g., DeNise et al., 1985; Johnson et al., 1990; review by Koots et al., 1994).

Estimates of the correlation between the direct and maternal genetic effects were negative and large in the univariate analyses with estimates of $-0.61(0.10)$, -0.67 (0.07), and $-0.65(0.09)$ for $\mathrm{BC}, \mathrm{BB}$, and $\mathrm{PA}$ weights, respectively. With the bivariate analyses using Model 1, the estimates of the correlation between direct and maternal genetic effects were lower and ranged from $-0.16(0.12)$ to $-0.41(0.12)$. The reason for this large difference in estimates of the direct-maternal genetic correlation between univariate and bivariate analyses is not clear but may be due to adjustments through the residual covariance matrix when accounting for more than one weight at a time.

Estimates of the proportion of variance due to direct permanent environment effects were small compared to the other components. With the univariate analyses all estimates were $0.00(0.05)$, and with the bivariate analyses the estimates ranged from $0.00(0.05)$ to 0.09
(0.04). Similarly, estimates for proportion of variance due to maternal permanent environment effects were relatively low. With the univariate analyses the estimates were 0.02 (0.02), 0.05 (0.02), and $0.06(0.02)$ for $\mathrm{BC}, \mathrm{BB}$, and $\mathrm{PA}$ weights, respectively, and with the bivariate analyses the estimates ranged from 0.00 (0.02) to $0.04(0.02)$.

The estimates of proportion of variance due to environmental effects were similar across analyses and models. With all models, the estimates with the univariate analyses were $0.26(0.01), 0.29(0.01)$, and $0.33(0.01)$ for the $\mathrm{BC}, \mathrm{BB}$, and $\mathrm{PA}$ weights, respectively, and ranged from $0.27(0.01)$ to 0.31 (0.01) with the bivariate analyses.

As expected, estimates of the genetic correlations between any two weights taken in different seasons were found to be extremely large, nearing unity. Estimates of the direct genetic correlation between pairs of weights in different seasons ranged from $0.97(0.01)$ to 0.99 (0.01). Estimates of maternal genetic correlations were also large, with estimates that ranged only from 0.99 (0.03) to 1.00 (0.01). Estimates of correlations between the direct genetic effect of one weight and the maternal genetic effect of another weight were similar to the correlation between the direct and maternal genetic effects of a single trait in the bivariate analyses and were moderate and negative, with estimates that ranged from $-0.12(0.12)$ to $-0.48(0.11)$. The strong correlations between any two weights suggest that any of the weights could be used to estimate breeding values for mature weight. These results also prompted the consideration of Models 4 to 6, which incorporate all possible weight information.

Estimates of correlations between direct permanent environmental effects were near unity for all three bivariate analyses with standard errors of approximately 0.04. Estimates of the correlation between pairs of maternal permanent environment effects varied; two estimates were near unity with an estimated standard error of 0.05 and one estimate was 0.00 with an estimated standard error that was out of the theoretical limits for a correlation. Because of the delta method used to estimate the standard errors, this unreasonable standard error is most likely due to the estimate being 0.00 . Finally, estimates of the temporary environmental correlations between pairs of weights ranged from 0.18 $(0.02)$ to $0.59(0.01)$. As might be expected, the smallest of these estimates was between $\mathrm{BC}$ and PA weights, which were the farthest apart in time, whereas consecutive weights (BC/BB and $\mathrm{BB} / \mathrm{PA})$ had estimates of environmental correlations that were moderate and similar to each other.

Model 4. Model 4 is identical to Model 1 with the exception of the added fixed factor for season by line $(\mathrm{S} \times \mathrm{L})$ combination to accommodate all measurements in one analysis. The results for this model are also shown in Table 6. With Model 4, all estimates were in agreement with those for the univariate analyses using Model 1. Direct heritability was estimated to be 0.69 
(0.07), maternal heritability was estimated to be 0.13 (0.03), and the correlation between the direct and maternal genetic effects was estimated to be -0.65 (0.07). Proportion of variance due to direct permanent environmental effects was negligible with an estimate of 0.00 (0.04). The estimate due to maternal permanent environmental effects was $0.04(0.01)$. The estimate due to temporary environmental effects was estimated to be 0.33 (0.01).

Although Model 4 results in approximately the same estimates of variance ratios as Model 1, more information is included in the latter analysis because weights from all seasons are considered simultaneously. These estimates and estimates near unity of genetic correlations with the bivariate analyses indicate that the most practical model for genetic evaluations for mature weight is Model 4. This recommendation also has the practical advantage that producers would not be restricted to when cows should be weighed and would allow for easy inclusion of the maximum amount of information.

Mature weight influences many economic aspects of the cow-calf operation, including maintenance, reproduction, and cull cow value, and, consequently, productivity and profitability. Therefore, a selection program that includes mature weight can be of benefit to producers who want to change or maintain a specific cow weight. Mature weight can be used in a selection index to change or maintain a desired cow weight while also selecting for other growth traits of interest, such as birth and weaning weight. To derive such an index, the correlations between mature weight and the other traits are needed.

\section{Implications}

Cow weight affects many aspects of production, including cow maintenance, reproduction, and cull cow value. Estimates of direct heritability for mature weight are high and therefore mature weight could be included in cow selection in order to change mature weight or to maintain a desired cow weight. Maternal effects, which have not previously been investigated or have been considered to be unimportant in analyses of mature weight, were statistically significant in this population of Hereford cattle. This result suggests that the most appropriate model for genetic evaluation for mature weight is one that considers maternal genetic effects and maternal permanent environmental effects of the dam as well as direct genetic effects of the cow and permanent environmental effects of the cow. Inclusion of a fixed factor in the model to account for different times of year when weights are taken would allow for the maximum number of records to be considered for prediction of breeding values.

\section{Literature Cited}

AAA. 2000. American Angus 2000 Spring Sire Evaluation Report. American Angus Association, St. Joseph, MO.

Arango, J., L. V. Cundiff, and L. D. Van Vleck. 2000. Genetic analysis of mature cow weight of crossbred beef cattle cows. J. Anim. Sci. 78(Suppl. 1):21 (Abstr.).

Boldman, K. G., L. A. Kriese, L. D. Van Vleck, and S. D. Kachman. 1993. A manual for use of MTDFREML. A set of programs to obtain estimates of variance and covariances. ARS-USDA, Clay Center, NE.

Brinks, J. S., R. T. Clark, N. M. Kieffer, and J. R. Quesenberry. 1962. Mature weight in Hereford range cows-heritability, repeatability, and relationship to calf performance. J. Anim. Sci. 21:501-504

Bullock, K. D., J. K. Bertrand, and L. L. Benyshek. 1993. Genetic and environmental parameters for mature weight and other growth measures in Polled Hereford cattle. J. Anim. Sci. 71:1737-1741.

Buttram, S. T., and R. L. Willham. 1989. Size and management effects on reproduction in first-, second-, and third-parity cows. J. Anim. Sci. 67:2191-2196.

DeNise, R. S. K., and J. S. Brinks. 1985. Genetic and environmental aspects of the growth curve parameters in beef cows. J. Anim. Sci. 61:1431-1440.

Dodenhoff, J., L. D. Van Vleck, S. D. Kachman, and R. M. Koch. 1998. Parameter estimates for direct, maternal, and grandmaternal genetic effects for birth weight and weaning weight in Hereford cattle. J. Anim. Sci. 76:2521-2527.

Henderson, C. R. 1984. Applications of Linear Models in Animal Breeding. University of Guelph, Ontario, Canada.

Johnson, Z. B., C. J. Brown, and A. H. Brown, Jr. 1990. Evaluation of growth patterns of beef cows. Arkansas Agric. Exp. Sta. Bull. 623, Fayetteville.

Kaps, M., W. O. Herring, and W. R. Lamberson. 1999. Genetic and environmental parameters for mature weight in Angus cattle. J. Anim. Sci. 77:569-574.

Koch, R. M., L. V. Cundiff, and K. E. Gregory. 1974. Selection in beef cattle. I. Selection applied and generation interval. J. Anim. Sci. 39:449-458.

Koch, R. M., L. V. Cundiff, and K. E. Gregory. 1994. Cumulative selection and genetic change for weaning or yearling weight or for yearling weight plus muscle score in Hereford cattle. J. Anim. Sci. 72:864-885.

Koch, R. M., L. V. Cundiff, and K. E. Gregory. 1995. Direct and maternal genetic responses to selection for weaning or yearling weight or for yearling weight and muscle score in Hereford cattle. J. Anim. Sci. 73:2951-2958.

Koots, K. R., J. P. Gibson, C. Smith, and J. W. Wilton. 1994. Analyses of published genetic parameter estimates for beef production traits. 1. Heritability. Anim. Breed. Abstr. 62:309-338.

McMorris, M. R., and J. W. Wilton. 1986. Breeding system, cow weight, and milk yield effects on various biological variables in beef production. J. Anim. Sci. 63:1361-1372.

Montaño-Bermudez, M., M. K. Nielsen, and G. H. Deutscher. 1990. Energy requirements for maintenance of crossbred beef cattle with different genetic potential for milk. J. Anim. Sci. 68:2279-2288.

Northcutt, S. L., and D. E. Wilson. 1993. Genetic parameter estimates and expected progeny differences for mature size in Angus cattle. J. Anim. Sci. 71:1148-1153.

Olson, T. A. 1994. The effect of cow size on reproduction. In: M. J. Fields and R. S. Sand (ed.). Factors Affecting Calf Crop. pp 243249. CRC Press, Ann Arbor, MI.

Owens, F. N., P. Dubeski, and C. F. Hanson. 1993. Factors that alter the growth and development of ruminants. J. Anim. Sci. 71:3138-3150.

Ramsey, F. L., and D. W. Schafer. 1997. The Statistical Sleuth: A Course in Methods of Data Analysis. Duxbury Press. Detroit, MI. 